\title{
Fire Fighter Suffers Fatal Heart Attack at Commercial Fire - New Jersey
}

\section{Executive Summary}

On June 8, 2014, a 54-year-old male volunteer firefighter (FF) responded to the scene of a commercial fire and performed interior fire suppression activities. The FF was part of an engine crew that advanced a charged 2.5-inch hoseline into the building. The FF served as the doorman to ensure the hoseline did not get caught on the door. After his second building entry, the FF exited the structure and then collapsed on the curb in the front of the building. On-scene emergency medical service (EMS) personnel immediately initiated cardiopulmonary resuscitation (CPR) and placed the FF in an on-scene ambulance for transport to the emergency department (ED). Despite resuscitation efforts on scene, during transport, and in the ED, the FF died. The death certificate and autopsy report, both completed by the Assistant Medical Examiner, listed the cause of death as "atherosclerotic cardiovascular disease," with physical exertion and smoke inhalation as contributory factors. The autopsy found severely blocked coronary arteries and evidence of an acute heart attack. Based on the FF's undiagnosed coronary heart disease (CHD), NIOSH investigators concluded that the physical exertion associated with fire suppression activities at this fire triggered the FF's heart attack and subsequent sudden cardiac death.

\section{Key Recommendations}

- $\quad$ Provide preplacement and annual medical evaluations to all fire fighters in accordance with NFPA 1582, Standard on Comprehensive Occupational Medical Program for Fire Departments

- Ensure fire fighters are cleared for duty by a physician knowledgeable about the physical demands of firefighting, the personal protective equipment used by fire fighters, and the various components of NFPA 1582

- $\quad$ Phase in a mandatory comprehensive wellness and fitness program for fire fighters.

The National Institute for Occupational Safety and Health (NIOSH), an institute within the Centers for Disease Control and Prevention (CDC), is the federal agency responsible for conducting research and making recommendations for the prevention of work-related injury and illness. In 1998, Congress appropriated funds to NIOSH to conduct a fire fighter initiative that resulted in the NIOSH Fire Fighter Fatality Investigation and Prevention Program, which examines line-of-duty deaths or on-duty deaths of fire fighters to assist fire departments, fire fighters, the fire service, and others to prevent similar fire fighter deaths in the future. The agency does not enforce compliance with state or federal occupational safety and health standards and does not determine fault or assign blame. Participation of fire departments and individuals in NIOSH investigations is voluntary. Under its program, NIOSH investigators interview persons with knowledge of the incident who agree to be interviewed and review available records to develop a description of the conditions and circumstances leading to the death(s). Interviewees are not asked to sign swom statements and interviews are not recorded. The agency's reports do not name the victim, the fire department or those interviewed. The NIOSH report's summary of the conditions and circumstances surrounding the fatality is intended to provide context to the agency's recommendations and is not intended to be definitive for purposes of determining any claim or benefit.

For further information, visit the program website at www.cdc.gov/niosh/fire or call toll free 1-800-CDC-INFO (1-800-232-4636). 


\section{Death in the line of duty... Nyosh}

\section{Fire Fighter Suffers Fatal Heart Attack at Commercial Fire - New Jersey}

\section{Introduction}

On June 8, 2014, a 54 year-old male volunteer FF suffered a fatal heart attack while operating at the scene of a commercial fire. NIOSH was notified of this fatality on June 10, 2014, by the U.S. Fire Administration. A contractor for the NIOSH Fire Fighter Fatality Investigation Team (the NIOSH investigator) contacted the fire department (FD) on March 26, 2015, to schedule the investigation, which took place on April 27, 2015.

During the investigation, the NIOSH investigator interviewed the following people:

- $\quad$ Chief of the FD

- $\quad$ Captain of the FD who was working with the FF

- $\quad$ EMS Chief who provided initial care

The NIOSH investigator reviewed the following documents in preparing this report:

- $\quad$ FD fire report

- $\quad$ FD standard operating guidelines

- $\quad$ FD dispatch records

- $\quad$ Police Department investigative report

- $\quad$ EMS (Ambulance) pre-hospital care report

- Hospital ED medical records

- $\quad$ Death certificate

- $\quad$ Medical examiner's (autopsy) report

- $\quad$ Medical records from preplacement medical screening

\section{Investigation}

On June 8, 2014, at 1756 hours the FD received an alarm for a structure fire in a commercial building. The structure was a single-story building (approximately $70 \times 70$ feet) with terracotta/concrete block foundation and walls. The flat roof was constructed of steel I-beams and steel column supports and covered with tin. The building housed a fabrication company that repaired hydraulic equipment and made custom metal fittings. The weather conditions were clear and sunny with an air temperature of approximately $70^{\circ}$ Fahrenheit and relative humidity of 75\% [Weather Channel 2015].

The first units arrived on scene at 1800 hours reporting heavy smoke conditions. Dispatch deployed three engines, a truck, a brush truck, chief car, and several support vehicles. Initial fire attack efforts were hampered because the fire was located in the back of the building and the rear door (steel) to the building was covered with a steel bar and there were no windows in the rear of the building from which to attack the fire. 


\section{Fire Fighter Suffers Fatal Heart Attack at Commercial Fire - New Jersey}

The FF was part of a four-person engine crew that was the third engine on scene arriving at 1805 hours. The FF and his crew were assigned to advance a 2.5-inch attack line into the building. Dressed in full personal protective equipment, the engine company made entry through the front door, but were inside for only about 5 minutes before exiting due to an inoperable thermal imaging camera.

The Chief of the FD arrived on scene at 1818 hours. After being briefed on ongoing operations including the difficulty gaining access to the back of the building, he assigned the FF's engine crew to reenter the front of the building and progress toward the rear of the building. After approximately 5 minutes, the FF and the entire engine crew were again forced to exit the building, this time due to rapidly deteriorating fire conditions and intense heat. The Chief checked on each engine crew member and then assigned the entire engine crew to rehabilitation (set up across the street). Nearly simultaneously, the Chief received a radio transmission that the roof was no longer safe for firefighting operations; he ordered all personnel to evacuate the building and activated the evacuation horn.

At approximately 1829 hours, with the Chief still standing in front of him, the FF sat down on the curb in front of the building and slumped onto his self-contained breathing apparatus (SCBA). Nearby fire fighters immediately rushed to the FF and carried him approximately 30 feet to the EMS personnel in the rehabilitation area. The FF was placed on a stretcher and his bunker gear was removed. He was quickly loaded into the ambulance which departed for the ED.

Initial assessment inside the ambulance revealed that the FF had no pulse, was not breathing, and was unresponsive. CPR was begun, an oral airway was secured with oxygen supplied by a non-rebreather bag. An external automated defibrillator was attached to the FF and three shocks were administered; the last shock at 1838 hours without a change in his heart rhythm or clinical condition.

The FF was admitted to the ED at 1842 hours in asystole and CPR in progress. The FF was intubated with an endotracheal tube, and a central line catheter was inserted. The FF was given cardiac medications through this central line, including epinephrine, atropine, sodium bicarbonate, and lidocaine, but he never regained a viable heart rhythm. Two attempts to defibrillate the FF were made at 1914 and 1916 hours without any change in his cardiac rhythm. At 1917 hours the FF was pronounced dead by the ED physician and resuscitation efforts were discontinued.

\section{Medical Findings}

The death certificate and autopsy, both completed by the Assistant Medical Examiner, listed the cause of death as "atherosclerotic cardiovascular disease" with physical exertion and smoke inhalation as contributory factors. Pertinent autopsy findings included "severely occlusive calcified atherosclerosis" in all three main coronary arteries, and evidence of an acute heart attack (myocardial infarction) based on segmental thrombosis of the left main coronary artery and appearance of the myocardium. The FF also had an enlarged heart (cardiomegaly), and left ventricular hypertrophy (LVH). His carboxyhemoglobin level was 7.2\%, suggesting minor to moderate exposure to carbon monoxide during this incident. See Appendix A for more detailed autopsy information. 


\section{Fire Fighter Suffers Fatal Heart Attack at Commercial Fire - New Jersey}

The FF was 74 inches tall and weighed about 233 pounds, giving him a body mass index of 29.9 kilograms per meter squared [CDC 2015]. The FF had not received a medical evaluation from the FD and little is known about his medical history. According to his wife, the FF had no history of cardiovascular disease, did not see a physician regularly, and took no medications. He was a nonsmoker. The FF worked as a driver for a shipping company, and reportedly had biannual medical evaluations to maintain his commercial driver's license. These records were not available to NIOSH at the time of this report.

\section{Fire Department}

The FD consists of 63 volunteers operating four stations serving approximately 6,500 people over 2 square miles. In 2014, the department responded to over 100 emergency calls.

\section{Membership and Training}

The FD requires new fire fighter applicants to be 18 years of age. Applicants must complete a form and be investigated by an "investigation committee" at the company level. If the investigation committee provides a positive recommendation, the potential member is presented to the entire company for a vote. If members vote to accept a potential member, a police department background check is performed. If the background check is acceptable, the potential member becomes a member and completes a state application form to be registered as a firefighter. Once registered with the State, the firefighter is enrolled in a County Fire Academy and required to complete a 192-hour state firefighter course (if he/she does not join the department with this credential).

\section{Preplacement Medical Evaluation}

The FD requires candidates to complete a respiratory medical evaluation questionnaire [29 CFR 1910.134]. If there are any positive responses, the candidate is referred to a Borough physician for evaluation. The FF joined this FD approximately 8 years earlier and completed the questionnaire at that time. In his responses, the FF answered no to all questions regarding cardiovascular or heart symptoms and the use of cardiovascular medications. Based on his responses, he did not receive a physician evaluation.

\section{Periodic Medical Evaluations/Return to Work Medical Evaluations}

The FD does not require annual medical evaluations for members. However the FD makes members aware of a state-wide program that provides free medical evaluations to all firefighters in New Jersey (Appendix 2). Firefighters who have had a serious injury or illness that requires hospitalization are required to be cleared for return to work by their primary care physician (PCP).

\section{Fitness/Wellness Programs}

The FD has no fitness equipment or program and offers no wellness program. 


\section{Fire Fighter Suffers Fatal Heart Attack at Commercial Fire - New Jersey}

\section{Discussion}

\section{Sudden Cardiac Death}

The most common risk factor for cardiac arrest and sudden cardiac death is CHD, defined as the buildup of atherosclerotic plaque in the coronary arteries [AHA 2012]. Risk factors for CHD include three non-modifiable factors (age older than 45, male gender, and family history of CHD) and six modifiable factors (smoking, hypertension, high blood cholesterol, obesity, physical inactivity, and diabetes mellitus) [National Cholesterol Education Program 2002; AHA 2015]. According to the FF's wife, the FF had no known cardiovascular health issues, did not have a PCP, and took no medications. On the FD's self-administered medical questionnaire completed when he joined the department in 2007, he had no symptoms of cardiovascular disease and was taking no medications.

The narrowing of the coronary arteries by atherosclerotic plaques occurs over many years, typically decades [Libby 2008]. However, the growth of these plaques probably occurs in a nonlinear, often abrupt fashion [Shah 1997]. Most heart attacks occur when a vulnerable plaque ruptures, causing a blood clot to form and occlude a coronary artery. This sudden blockage is primarily due to blood clots (thrombosis) forming on top of atherosclerotic plaques [Libby 2013].

Establishing a recent (acute) heart attack requires one or more of the following: characteristic electrocardiogram changes, elevated cardiac enzymes, or coronary artery thrombus. At autopsy, the FF had evidence of a thrombus in his left main coronary artery confirming an acute heart attack.

\section{Cardiomegaly/Left Ventricular Hypertrophy}

The autopsy revealed that the FF had cardiomegaly and LVH. Both conditions independently increase the risk for sudden cardiac death [Levy et al. 1990]. Hypertrophy of the left ventricle is relatively common among individuals with long-term hypertension, a heart valve problem, or chronic CHD and ischemia to the heart muscle [Siegel 1997]. The FF had severe CHD at autopsy.

\section{Carbon Monoxide, Carboxyhemoglobin Levels, and Cardiac Effects.}

Carbon monoxide (CO) is a component of fire smoke. When inhaled, CO crosses the alveolar (lung) membrane gaining access to the body's blood stream. In blood, the $\mathrm{CO}$ can dissolve in the serum and displace oxygen on the hemoglobin molecule forming carboxyhemoglobin ( $\mathrm{COHb})$. CO disrupts the delivery of, and the intercellular use of, oxygen leading to hypoxia (inadequate oxygen supply) [Alonso et al. 2003; Roderique et al. 2015]. The brain and the heart are the organs most vulnerable to hypoxia, thus, the symptoms and signs associated with CO poisoning include headache, dizziness, weakness, nausea, confusion, fast heart rate, and shortness of breath [Ernst and Zibrak 1998]. During this incident, the FF did not express any of these symptoms.

$\mathrm{COHb}$ levels in the blood are used to assess $\mathrm{CO}$ exposure and $\mathrm{CO}$ poisoning. COHb levels in nonsmokers are typically 1-3\%, while cigarette smokers have levels that range from $4-8 \%$ [Castelden and Cole 1975]. The FF had a COHb of 7.3\%, suggesting some CO exposure during his response at this incident. While COHb levels of 6\% can increase the frequency of ventricular arrhythmias among patients with ischemic heart disease [Sheps et al. 1990], it is unclear whether CO has an acute effect on 


\section{Fire Fighter Suffers Fatal Heart Attack at Commercial Fire - New Jersey}

plaque rupture (e.g., an acute heart attack) [Zevin et al. 2001]. In summary, the FF was exposed to carbon monoxide at some point during this incident causing an elevation of his COHb level. It is unclear what role, if any, this exposure had in triggering his heart attack and sudden cardiac death.

\section{Physiological Stress of Firefighting}

Firefighting is widely acknowledged to be physically demanding. Firefighting activities require fire fighters to work at near maximal heart rates for long periods. An increase in heart rate typically occurs in response to the initial alarm and persists throughout the course of fire suppression activities [Barnard and Duncan 1975; Lemon and Hermiston 1977; Manning and Griggs 1983; Smith et al. 2001]. Even when energy costs are moderate (as measured by oxygen consumption) and work is performed in a thermoneutral environment, heart rates may be high (over 170 beats per minute) owing to the insulating properties of the personal protective clothing [Smith et al. 1995]. Recent evidence also indicates the firefighting results in increased clotting potential which persists for 2 hours after firefighting activities [Smith et al. 2014].

Epidemiologic studies in the general population have found that heavy physical exertion can trigger a heart attack and/or sudden cardiac death [Tofler et al. 1992; Mittleman et al. 1993; Willich et al. 1993; Albert et al. 2000]. Epidemiologic studies among fire fighters have shown that fire suppression, training, alarm response, or strenuous physical activity on the job, in the preceding 12 hours, increases the risk for a sudden cardiac event [Kales et al. 2003; Hales et al. 2007; Kales et al. 2007].

In summary, the FF had been performing firefighting activity in full PPE at a commercial fire for about 24 minutes. NIOSH investigators conclude that the strenuous work associated with firefighting duties triggered the FF's fatal heart attack.

\section{Occupational Medical Standards for Structural Fire Fighters}

To reduce the risk of sudden cardiac arrest or other incapacitating medical conditions among fire fighters, the National Fire Protection Association (NFPA) developed NFPA 1582, Standard on Comprehensive Occupational Medical Program for Fire Departments [NFPA 2013]. This voluntary industry standard provides (1) the components of a preplacement and annual medical evaluation and (2) medical fitness for duty criteria. The FD only requires a self-administered medical questionnaire for candidate and does not require any medical evaluations for incumbents. If the FD had a comprehensive medical evaluation in place, perhaps the FF's cardiac condition could have been identified, evaluated, and treated prior to this incident.

\section{Recommendations}

Recommendation \#1: Provide preplacement and annual medical evaluations to all firefighters in accordance with NFPA 1582, Standard on Comprehensive Occupational Medical Program for Fire Departments.

Discussion: Guidance regarding the content of these medical evaluations can be found in NFPA 1582 [NFPA 2013]. These evaluations are performed to determine fire fighters' medical ability to perform 


\section{Fire Fighter Suffers Fatal Heart Attack at Commercial Fire - New Jersey}

duties without presenting a significant risk to the safety and health of themselves or others. To ensure improved health and safety of candidates and members, and to ensure continuity of medical evaluations, it is recommended the FD comply with this recommendation, particularly the section addressing CHD. However, the FD is not legally required to follow the NFPA standard. Applying this recommendation involves economic repercussions and may be particularly difficult for smaller fire departments to implement.

To overcome the financial obstacle of medical evaluations, the FD could urge current members to get annual medical clearances from their private physicians or their employer. If the FD had a FD physician reviewing medical records from other employers (i.e., the FF's commercial driver's license exam), perhaps this FF's CHD could have been identified, evaluated, and treated.

Another option is having the annual medical evaluations (vital signs, height, weight, visual acuity, and electrocardiogram) completed by paramedics and emergency medical technicians from the local ambulance service. This information could then be provided to a community physician (perhaps volunteering his or her time), who could review the data and provide medical clearance (or further evaluation, if needed).

The more extensive portions of the medical evaluations could be performed by a private physician at the fire fighter's expense (personal or through insurance), provided by a physician volunteer, or paid for by the FD, city, or State. In the State of New Jersey a medical evaluation program titled "A Gift from Captain Buscio” was initiated by Captain’s Buscio’s widow. It provides free medical evaluations to New Jersey fire fighters (Appendix 2). Sharing the financial responsibility for these evaluations between fire fighters, the FD, the city, the State, and physician volunteers may reduce the negative financial impact on recruiting and retaining needed fire fighters.

\section{Recommendation \#2: Ensure fire fighters are cleared for duty by a physician knowledgeable about the physical demands of firefighting, the personal protective equipment used by fire fighters, and the various components of NFPA 1582.}

Discussion: According to NFPA 1582, the FD should have an officially designated physician who is responsible for guiding, directing, and advising the members with regard to their health, fitness, and suitability for duty [NFPA 2013]. The physician should review job descriptions and essential job tasks required for all FD positions to understand the physiological and psychological demands of firefighting and the environmental conditions under which fire fighters perform, as well as the personal protective equipment they must wear during various types of emergency operations. In addition, this physician should oversee all fitness for duty recommendations provided by PCPs and have the final authority for all medical fitness for duty decisions. To ensure the FD physician or other PCP is familiar with NFPA 1582, the NIOSH investigators recommend the FD provide a copy of NFPA 1582 or a link to the NFPA website where a copy could be purchased or viewed on-line at no charge. 


\section{Fire Fighter Suffers Fatal Heart Attack at Commercial Fire - New Jersey}

\section{Recommendation \#3: Phase in a mandatory comprehensive wellness and fitness program to reduce risk factors for cardiovascular disease and improve cardiovascular capacity.}

Discussion: Guidance for fire department wellness/fitness programs to reduce risk factors for cardiovascular disease and improve cardiovascular capacity is found in NFPA 1583, Standard on Health-Related Fitness Programs for Fire Fighters, the IAFF/IAFC Fire Service Joint Labor Management Wellness/Fitness Initiative, the National Volunteer Fire Council Health and Wellness Guide, and in Firefighter Fitness: A Health and Wellness Guide [USFA 2004; IAFF, IAFC 2008; NFPA 2008; Schneider 2010]. Worksite health promotion programs have been shown to be cost effective by increasing productivity, reducing absenteeism, and reducing the number of work-related injuries and lost work days [Stein et al. 2000; Aldana 2001]. Fire service health promotion programs have been shown to reduce CHD risk factors and improve fitness levels, with mandatory programs showing the most benefit [Dempsey et al. 2002; Womack et al. 2005; Blevins et al. 2006]. A study conducted by the Oregon Health and Science University reported a savings of more than \$1 million for each of four large fire departments implementing the IAFF/IAFC wellness/fitness program compared to four large fire departments not implementing a program. These savings were primarily due to a reduction of occupational injury/illness claims with additional savings expected from reduced future nonoccupational healthcare costs [Kuehl et al. 2013]. The department should implement a wellness and fitness program to help ensure that their members are physically prepared for the strenuous work of firefighting.

\section{References}

AHA [2015]. Understand your risk of heart attack. American Heart Association. [http://www.heart.org/HEARTORG/Conditions/HeartAttack/UnderstandYourRiskofHeartAttack/Unde rstand-Your-Risk-of-Heart-Attack_UCM_002040_Article.jsp]. Date accessed: May 2015.

Albert CM, Mittleman MA, Chae CU, Lee IM, Hennekens CH, Manson JE [2000]. Triggering of sudden death from cardiac causes by vigorous exertion. N Engl J Med 343(19):1355-1361.

Aldana SG [2001]. Financial impact of health promotion programs: a comprehensive review of the literature. Am J Health Promot 15:296-320.

Alonso JR, Cardellach F, Lopez S, Casademont J, Miro O [2003]. Carbon monoxide specifically inhibits cytochrome c oxidase of human mitochondrial respiratory chain. Pharmacol Toxicol 93(3):142-146.

Barnard RJ, Duncan HW [1975]. Heart rate and ECG responses of firefighters. J Occup Med 17(4): 247-250.

Blevins JS, Bounds R, Armstrong E, Coast JR [2006]. Health and fitness programming for fire fighters: does it produce results? Med Sci Sports Exerc 38(5):S454. 


\section{Fire Fighter Suffers Fatal Heart Attack at Commercial Fire - New Jersey}

Castelden CM, Cole PV [1975]. Carboxyhaemoglobin levels of smokers and non-smokers working in the City of London. Brit J Ind Med 32;115-119.

CDC [2015]. Assessing your weight. Centers for Disease Control and Prevention. [http://www.cdc.gov/healthyweight/assessing/index.html]. Date accessed: May 2015.

CFR. Code of Federal Regulations. Washington, DC: U.S. Government Printing Office, Office of the Federal Register

Davies MJ [1992]. Anatomic features in victims of sudden coronary death. Coronary artery pathology. Circulation 85[Suppl I]:I-19-24.

Dempsey WL, Stevens SR, Snell CR [2002]. Changes in physical performance and medical measures following a mandatory firefighter wellness program. Med Sci Sports Exerc 34(5):S258.

Ernst A, Zibrak JD [1998]. Carbon monoxide poisoning. N Engl J Med 339(22):1603-1608.

Hales T, Jackson S, Baldwin T [2007]. NIOSH Alert: Preventing Fire Fighter Fatalities Due to Heart Attacks and Other Sudden Cardiovascular Events. Department of Health and Human Services, Public Health Service, Centers for Disease Control and Prevention, National Institute for Occupational Safety and Health Publication No. 2007-133. [http://www.cdc.gov/niosh/docs/2007-133/]. Date Accessed: May 2015.

IAFF, IAFC [2008]. The fire service joint labor management wellness/fitness initiative. 3rd ed. Washington, DC: International Association of Fire Fighters, International Association of Fire Chiefs.

Kales SN, Soteriades ES, Christoudias SG, Christiani DC [2003]. Fire fighters and on-duty deaths from coronary heart disease: a case control study. Environ Health 2(1):14.

Kales SN, Soteriades ES, Christophi CA, Chirstiani DC [2007]. Emergency duties and deaths from heart disease among fire fighters in the United States. New Engl J Med 356(12):1207-1215.

Kuehl KS, Elliot DL, Goldberg L, Moe EL, Perrier E, Smith J [2013]. Economic benefit of the PHLAME wellness programme on firefighter injury. Occup Med 63(3):203-209.

Lemon PWR, Hermiston RT [1977]. The human energy cost of fire fighting. J Occup Med 19(8):558565

Levy D, Garrison RJ, Savage DD, Kannel WB, Castelli WP [1990]. Prognostic implications of echocardiographically determined left ventricular mass in the Framingham Heart Study. N Engl J Med 323(24):1706-1707. 


\section{Fire Fighter Suffers Fatal Heart Attack at Commercial Fire - New Jersey}

Libby P [2008]. The pathogenesis, prevention, and treatment of atherosclerosis. In: Fauci AS, Braunwald E, Kasper DL, Hauser SL, Longo DL, Jameson JL, Loscalzo J, eds. Harrison's principles of internal medicine. 17th ed. New York: McGraw-Hill, pp. 1501-1509.

Libby P [2013]. Mechanisms of acute coronary syndromes and their implications for therapy. N Engl J Med 368(21):2004-4013.

Manning JE, Griggs TR [1983]. Heart rates in fire fighters using light and heavy breathing equipment: Similar near-maximal exertion in response to multiple work load conditions. J Occup Med. 25(3): 215218.

Mittleman MA, Maclure M, Tofler GH, Sherwood JB, Goldberg RJ, Muller JE [1993]. Triggering of acute myocardial infarction by heavy physical exertion. N Engl J Med 329(23):1677-1683.

NFPA [2008]. Standard on health-related fitness programs for fire fighters. Quincy, MA: National Fire Protection Association. NFPA 1583.

NFPA [2013]. Standard on comprehensive occupational medical program for fire departments. Quincy, MA: National Fire Protection Association. NFPA 1582.

National Cholesterol Education Program [2002]. Third Report of the National Cholesterol education Program (NCEP) Expert Panel on Detection, Evaluation, and Treatment of High Blood Cholesterol in Adults (Adult treatment Panel III). NIH Publication No. 02-5215. National Institutes of Health, National Heart, Lung, and Blood Institute. Washington: Government Printing Office.

Roderique JD, Josef CS, Feldman MJ, Spiess BD [2015]. A modern literature review of carbon monoxide poisoning theories, therapies, and potential targets for therapy advancement. Toxicology 334:45-51.

Schneider EL [2010]. Firefighter fitness: a health and wellness guide. New York: Nova Science Publishers.

Shah PK [1997]. Plaque disruption and coronary thrombosis: new insight into pathogenesis and prevention. Clin Cardiol 20(11 Suppl2):II-38-44.

Sheps DS, Herbst MC, Hinderliter AL, Adams KF, Ekelund LG, O'Neil JJ, Goldstein GM, Bromberg PA, Dalton JL, Balienger MN, Davis SM, Koch GG [1990]. Production of arrhythmias by elevated carboxyhemoglobin in patients with coronary artery disease. Annals of Intern Med 113;343-351.

Siegel RJ [1997]. Myocardial hypertrophy. In: Bloom S, ed. Diagnostic criteria for cardiovascular pathology acquired diseases. Philadelphia, PA: Lippencott-Raven, pp. 55-57. 


\section{Fire Fighter Suffers Fatal Heart Attack at Commercial Fire - New Jersey}

Smith DL, Horn GP, Petruzzello SJ, Fahey G, Woods J, Fernhall B [2014]. Clotting and fibrinolytic changes after firefighting activities. Med Sci Sports Exerc 46(3):448-454.

Smith DL, Horn GP, Petruzzello SJ, Freund G, Woods J, Cook M, Goldstein E, Fernhall B [2014]. Effect of Obesity on Acute Hemostatic Responses to Live-Fire Training Drills. Am J Cardiol 114:1768-1771.

Smith DL, Manning TS, Petruzzello SJ [2001]. Effect of strenuous live-drills on cardiovascular and psychological responses of recruit fire fighters. Ergonomics 44(3): 244-254.

Smith DL, Petruzzello SJ, Kramer JM, Warner SE, Bone BG, Misner JE [1995]. Selected physiological and psychobiological responses of physical activity in different configurations of firefighting gear. Ergonomics 38(10): 2065-2077.

Stein AD, Shakour SK, Zuidema RA [2000]. Financial incentives, participation in employer sponsored health promotion, and changes in employee health and productivity: HealthPlus health quotient program. J Occup Environ Med 42(12):1148-1155.

Tofler GH, Muller JE, Stone PH, Forman S, Solomon RE, Knatterud GL, Braunwald E [1992]. Modifiers of timing and possible triggers of acute myocardial infarction in the Thrombolysis in Myocardial Infarction Phase II (TIMI II) Study Group. J Am Coll Cardiol 20(5):1049-1055.

USFA [2004]. Health and Wellness Guide for the Volunteer Fire and Emergency Services. Emmitsburg, MD: Federal Emergency Management Agency; United States Fire Administration. Publication No. FA-321.

Weather Channel [2015]. Historical Weather. [http://www.wunderground.com/history].

Willich SN, Lewis M, Lowel H, Arntz HR, Schubert F, Schroder R [1993]. Physical exertion as a trigger of acute myocardial infarction. N Engl J Med 329(23):1684-1690.

Womack JW, Humbarger CD, Green JS, Crouse SF [2005]. Coronary artery disease risk factors in firefighters: effectiveness of a one-year voluntary health and wellness program. Med Sci Sports Exerc 37(5):S385.

Zevin S, Saunders S, Gourlay SG, Jacob III P, Benowitz NL [2001]. Cardiovascular effects of carbon monoxide and cigarette smoking. J Am Coll Cardiol 38(6):1633-1638.

\section{Investigator Information}

This incident was investigated by the NIOSH Fire Fighter Fatality Investigation and Prevention Program, Cardiovascular Disease Component located in Cincinnati, Ohio. Denise L. Smith, Ph.D, led the investigation and coauthored the report. Dr. Smith is professor of Health and Exercise Sciences, and Director of the First Responder Health and Safety Laboratory at Skidmore College. She is a 


\section{Fire Fighter Suffers Fatal Heart Attack at Commercial Fire - New Jersey}

member of the NFPA Technical Committee on Occupational Safety and Health. Dr. Smith was working as a contractor with the NIOSH Fire Fighter Fatality Investigation and Prevention Program, Cardiovascular Disease Component during this investigation. Thomas Hales, MD, MPH, provided medical consultation and coauthored the report. Dr. Hales is a member of the NFPA Technical Committee on Occupational Safety and Health, and Vice Chair of the Public Safety Medicine Section of the American College of Occupational and Environmental Medicine (ACOEM).

\section{Disclaimer}

Mention of any company or product does not constitute endorsement by the National Institute for Occupational Safety and Health (NIOSH). In addition, citations to Web sites external to NIOSH do not constitute NIOSH endorsement of the sponsoring organizations or their programs or products. Furthermore, NIOSH is not responsible for the content of these Web sites. 


\section{Fire Fighter Suffers Fatal Heart Attack at Commercial Fire - New Jersey}

\section{Appendix One}

\section{Autopsy Findings}

- Heart size and structure

o Heart weight $=560$ grams (expected weight 403 grams; lower $95 \%$ confidence limit 305 grams and upper $95 \%$ confidence limit 531 grams for a male weighing 234 pounds [the FF weighed 233 pounds]) [Silver and Silver 2001]

o Left ventricular hypertrophy noted

- Coronary arteries

o Severely occlusive calcified trivascular atherosclerosis

o Segmental thrombosis of left main stem confirming an acute myocardial infarction (MI)

o Myocardium changes of the postero-lateral wall of left ventricle suggesting an acute MI

o $\quad 80-90 \%$ lumen occlusion of all major arteries

- No evidence of valvular disease

- No evidence for a pulmonary embolus

- Mild atherosclerosis of aorta

- Negative drug screen

- Carboxyhemoglobin $(\mathrm{COHb})=7.2 \%$, suggesting the $\mathrm{FF}$ was exposed to carbon monoxide during this incident [Castelden and Cole, 1975; Sheps et al. 1990].

\section{References}

Castelden CM, Cole PV [1975]. Carboxyhaemoglobin levels of smokers and non-smokers working in the City of London. Brit J Ind Med 32;115-119.

Colucci WS, Braunwald E [1997]. Pathophysiology of heart failure. In: Braunwald, ed. Heart disease. 5th ed. Philadelphia, PA: W.B. Saunders Company, p. 401.

Sheps DS, Herbst MC, Hinderliter AL, Adams KF, Ekelund LG, O'Neil JJ, Goldstein GM, Bromberg PA, Dalton JL, Balienger MN, Davis SM, Koch GG [1990]. Production of arrhythmias by elevated carboxyhemoglobin in patients with coronary artery disease. Annals of Intern Med 113;343-351.

Silver MM, Silver MD [2001]. Examination of the heart and of cardiovascular specimens in surgical pathology. In: Silver MD, Gotlieb AI, Schoen FJ, eds. Cardiovascular pathology. 3rd ed. Philadelphia, PA: Churchill Livingstone, pp. 8-9. 


\section{Fire Fighter Suffers Fatal Heart Attack at Commercial Fire - New Jersey}

\section{Appendix Two:}

A brochure describing free medical evaluations for fire fighters from the State of New Jersey
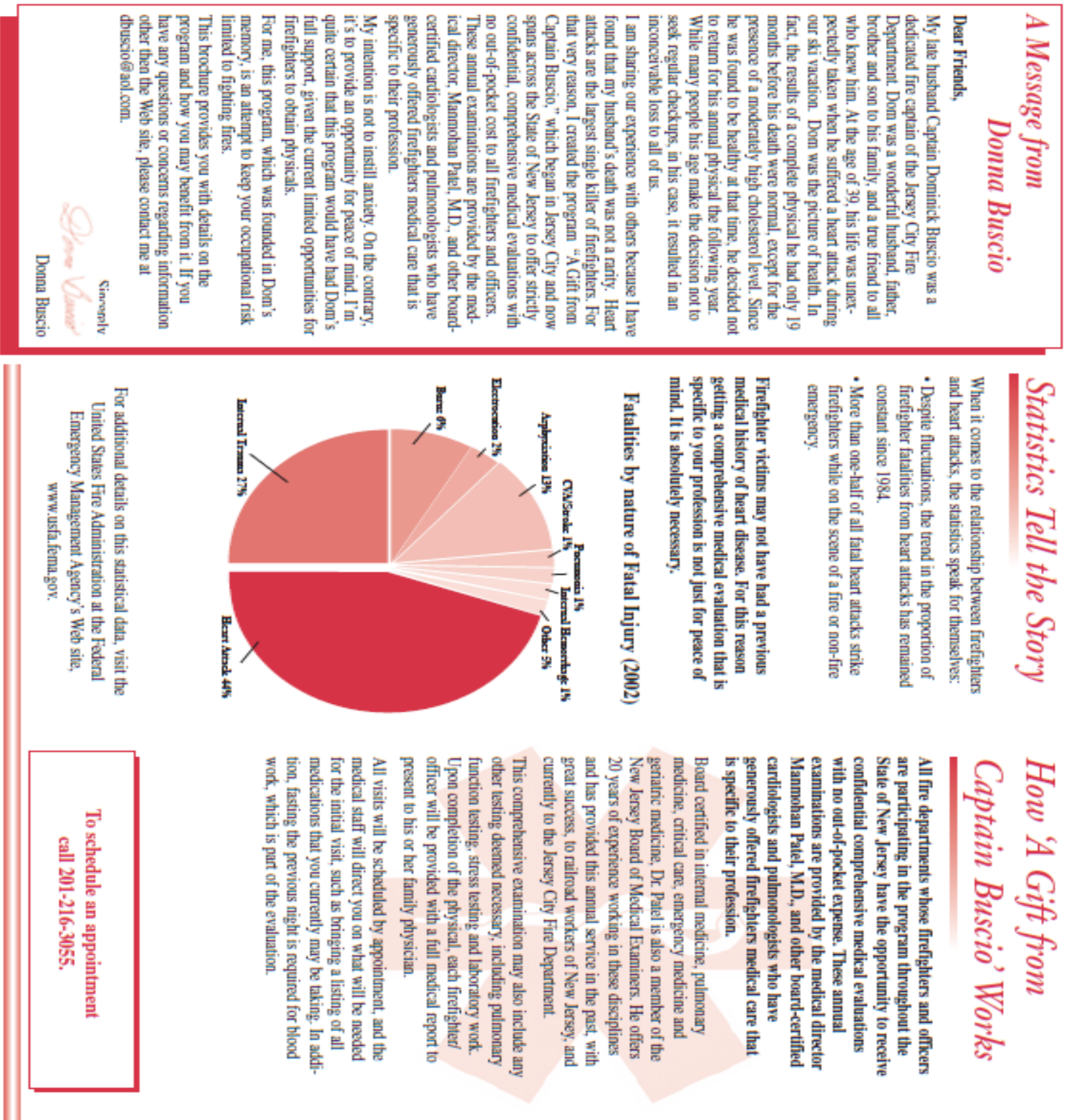